\title{
Wnt3a induces exosome secretion from primary cultured rat microglia
}

\author{
Claudie Hooper ${ }^{1 *}$, Ricardo Sainz-Fuertes ${ }^{1}$, Steven Lynham ${ }^{1}$, Abdul Hye ${ }^{1}$, Richard Killick1, Alice Warley², \\ Cecilia Bolondi ${ }^{1}$, Jennifer Pocock ${ }^{3}$ and Simon Lovestone ${ }^{1}$
}

\begin{abstract}
Background: Microglia, the immune effector cells of the CNS and the signaling molecule Wnt, both play critical roles in neurodevelopment and neurological disease. Here we describe the inducible release of exosomes from primary cultured rat microglia following treatment with recombinant carrier-free Wnt3a.

Results: Wnt3a was internalised into microglia, being detectable in early endosomes, and secreted in exosomes through a GSK3-independent mechanism. Electron microscopy demonstrated that exosomes were elliptical, electron-dense $(100 \mathrm{~nm})$ vesicles that coalesced with time in vitro. In contrast to microglia, primary cortical neurons released exosomes constitutively and the quantity of exosomes released was not altered by Wnt3a treatment. The proteomic profile of the microglial-derived exosomes was characterised using liquid chromatography-tandem mass spectrometry (LC/MS/MS) and the vesicles were found to be associated with proteins involved in cellular architecture, metabolism, protein synthesis and protein degradation including $\beta$-actin, glyceraldehyde-3-phosphate dehydrogenase, ribosomal subunits and ubiquitin (45 proteins in total). Unlike lipopolysaccharide, Wnt3a did not induce a neurotoxic, pro-inflammatory phenotype in primary microglia.
\end{abstract}

Conclusion: These findings reveal a novel mechanism through which Wnt3a signals in microglia resulting in the release of exosomes loaded with proteinaceous cargo.

Keywords: Wnt3a, Glycogen synthase kinase, Microglia, Exosomes, Signaling, Proteomic

\section{Background}

Microglia are the main immune effectors of the CNS contributing to developmental processes and in the adult to metabolite removal, trophic support through the secretion of growth factors and to the clearance of toxic factors and debris [1]. In response to injury or disease microglia proliferate and transform into active "brain macrophages' to combat pathology and provide neuroprotection [2]. However, in this chronically activated state microglial-derived mediators can become detrimental to neuronal survival if the activating signal and thus inflammatory mediator secretion persists.

Wnt proteins are a family of cysteine rich glycoproteins that play a role during development and in tumorigenesis and have recently been implicated in the pathogenesis of Alzheimer's disease (AD); a chronic

\footnotetext{
* Correspondence: claudie.1.hooper@kcl.ac.uk

'King's College London, MRC Centre for Neurodegenerative Research,

Institute of Psychiatry, De Crespigny Park, Denmark Hill, London SE5 8AF, UK Full list of author information is available at the end of the article
}

neurodegenerative disease characterised by the presence of neurofibrillary tangles and $\beta$-amyloid $(\mathrm{A} \beta$ ) plaques $[3,4]$. There are 19 human WNT genes, several of which encode alternatively-spliced isoforms, which are emerging to play diverse roles in the adult CNS $[5,6]$. There are three main branches to the Wnt signaling system: the $\beta$-catenin/GSK3 pathway, the planar cell polarity pathway and the $\mathrm{Wnt} / \mathrm{Ca}^{2+}$ pathway. Recently, it has been shown that Wnt3a can induce $\beta$-catenin signaling in N13-microglial-like cells [7]. In addition to these well characterised Wnt signaling cascades there are other Wnt pathways emerging including the Wnt-RAP1, WntPKA, Wnt-RYK, Wnt-aPKC, Wnt-GSK3 microtubule signaling, WntROR2 and the Wnt-mTOR pathways [8-10]. Wnt proteins initiate signaling through binding Frizzled. Ten Frizzled isoforms (FZD 1-10) have been identified in humans and mouse microglia have been shown to express FZD 4, 5, 7 and 8 as well as the Frizzled co-receptors LRP5/6 [11]. Signal specificity is complex, but may be achieved through cell specific

\section{Biomed Central}


Table 1 Proteomic profile of micriglial-derived exosomes induced by Wnt3a treatment

\begin{tabular}{|c|c|c|c|}
\hline Protein & MW (Da) & Peptides matched & Function \\
\hline Laminin subunit beta-1 & 196776 & 1 & Basement membrane \\
\hline Clathrin heavychain 1 & 191477 & 9 & Membrane trafficing \\
\hline Laminin subunit gamma-1 & 177185 & 2 & Basement membrane \\
\hline Alpha-1-macroglobulin & 167019 & 1 & Inhibits proteases \\
\hline Peroxidasin homolog & 165029 & 16 & ECM peroxidase (basement membrane) \\
\hline Nidogen-1 & 136536 & 1 & Basement membrane \\
\hline Adipocyte enhancer-building protein 1 & 130847 & 4 & Transcriptional repressor (cholesterol metabolism) \\
\hline Major vault protein & 95739 & 5 & Drug resistance \\
\hline Transitional endoplasmatic reticulum ATPase & 89293 & 8 & Budding of vesicels from ER \\
\hline Integrin beta-2 & 84970 & 2 & Cell adhesion \\
\hline Heat shock protein HS 90-alpha & 84762 & 1 & Chaperone (folding of cyctolic proteins) \\
\hline V-type proton ATPases catalytic subunit A & 68283 & 1 & Proton pump \\
\hline Transketolase & 67601 & 1 & Cytosolic metabolic enzyme \\
\hline Galectin-3-binding protein & 63701 & 1 & Cell adhesion via integrins \\
\hline Dihydropyrimidinase-related protein & 62157 & 1 & CRMP (schizophrenia risk gene) development \\
\hline ATP synthase subunit alpha, mitochondrial & 59717 & 3 & Mitochondrial enzyme \\
\hline T-complex protein 1 subunit eta & 59614 & 1 & Chaperone (folding of cytosolic proteins) \\
\hline Pyruvate kinase isozymes M1/M2 & 57781 & 7 & Glycolysis (cytosol) \\
\hline T-complex protein 1 subunit beta & 57422 & 1 & Chaperone (folding of cytosolic proteins) \\
\hline Matrix metalloproteinase-19 & 57321 & 2 & Secreted protease (ECMremodelling) \\
\hline Cystosol aminopeptidase & 56115 & 1 & Protein turnover \\
\hline Vitronectin & 54271 & 1 & Extracellular matrix \\
\hline Lipoprotein lipase & 53049 & 2 & Lipid hydrolysis \\
\hline Tubulin alpha-1B chain & 50120 & 3 & Structural \\
\hline Tubulin beta-5 chain & 49639 & 4 & Structural \\
\hline Actin, cytoplasmic 2 & 41766 & 28 & Structural \\
\hline Actin, cytoplasmic 1 & 41710 & 3 & Structural \\
\hline Protein Wnt-3a & 39232 & 15 & Treatment \\
\hline Annexin A2 & 38654 & 2 & Structural/ inhibits phospolipase A2 (anti inflam)/Apoptosis \\
\hline Annexin A3 & 36341 & 9 & Structural/ inhibits phospolipase A2 (anti inflam)/Apoptosis \\
\hline Annexin A4 & 35826 & 2 & Structural/ inhibits phospolipase A2 (anti inflam)/Apoptosis \\
\hline Apolipoprotein E & 35731 & 10 & Lipoprotein \\
\hline Glyceraldehyde-3-phosphate dehydrogenase & 35725 & 8 & Glycolysis(cytosol) \\
\hline
\end{tabular}


Table 1 Proteomic profile of micriglial-derived exosomes induced by Wnt3a treatment (Continued)

\begin{tabular}{|c|c|c|c|}
\hline Annexin A5 & 35722 & 1 & Structural/ inhibits phospolipase A2 (anti inflam)/Apoptosis \\
\hline $40 \mathrm{~S}$ ribosomal protein SA & 32803 & 3 & Protein synthesis \\
\hline $40 S$ ribosomal protein SA & 32803 & 1 & Protein synthesis \\
\hline $40 \mathrm{~S}$ ribosomal protein $\mathrm{S} 3 \mathrm{a}$ & 29926 & 1 & Protein synthesis \\
\hline Proteasome subunit beta type-7 & 29908 & 2 & Proteasomal degradation \\
\hline $40 S$ ribosomal protein $\mathrm{S} 3$ & 26657 & 5 & Protein synthesis \\
\hline Proteinsome subunit alpha type-2 & 25910 & 1 & Proteasomal degradation \\
\hline $40 S$ ribosomal protein 58 & 24190 & 2 & Protein synthesis \\
\hline 40 S ribosomal protein $\mathrm{S} 5$ & 22864 & 1 & Protein synthesis \\
\hline Ferritin heavy chain & 21113 & 2 & Intracellular iron storage \\
\hline Ferritin light chain 1 & 20736 & 10 & Intracellular iron storage \\
\hline Ubiquitin & 8560 & 1 & Proteasomal degradation \\
\hline
\end{tabular}

Microglia ( 2500000 cells) were treated with Wnt3a (10 nM) for 8 hours in SFM. Cell culture medium was collected, centrifuged at 10000xg for 10 minutes, concentrated using 3kDa centrifugal devices and exosomes were isolated at $100000 \mathrm{xg}$. Exosomal proteins were separated by SDS-PAGE (10)\% and visualised using coomassie blue. The exosomal proteome was subsequently interrogated using LC/MS/MS and database searching. Proteins are listed according to their molecular weight and the number of peptides matched per protein is presented along with protein function. 
expression of Frizzled isoforms, which form homo/hetero-oligomers with different affinities for Wnt ligands or through the association of Frizzled with different combinations of co-receptor [8-10,12].

A number of extracellular membrane-bound vesicles have been identified to date including exosomes (which form the focus of this study), microvesicles, membrane particles and apoptotic blebs [13]. Extracellular vesicles are present in a number of physiological fluids including CSF [14], urine, amniotic fluid, saliva and blood [15]. Functions of extracellular vesicles are varied and include inter-cellular communication through the transmission of proteins, mRNA and miRNA, the removal of defective or effete proteins, antigen presentation and the formation of morphogen gradients [16]. Extracellular vesicles are also involved in the propagation of tumors as well as viral and prion infections. Furthermore, $A \beta$ is secreted in exosomes, exosomal proteins accumulate in $A \beta$ plaques in $\mathrm{AD}$ [17] and insulin-degrading enzyme can act to degrade $A \beta$ inside exosomes [18]. Exosomes derived from neuronal-like cells have also been found to contain $\alpha$-synuclein, a hallmark pathological feature of Parkinson's disease, and application of such vesicles to neurons confers cytotoxicity [19]. This suggests that exosomal signaling might play important, but as yet incompletely understood roles in the CNS.

Exosomes form within sorting endosomes giving rise to multi-vesicular endosomes (or multivesicular bodies) [20]. Multi-vesicular endosomes subsequently fuse with the plasma membrane releasing exosomes or multivesicular endosomes are directed to lysosomes for degradation. Secretory vesicles might also form within other organelles generating exosome-like vesicles.

In this study we sought to investigate the effects of Wnt3a on the secretions from primary rat microglia considering the important roles that microglia and Wnt both play in development and in neurological disease. Interestingly, we found that primary microglia secreted exosomes following stimulation with Wnt3a. In contrast, primary cortical neurons released such vesicles in a constitutive manner. Microglial-derived exosomes were approximately $100 \mathrm{~nm}$ in diameter and contained a variety of ontologically different proteins; some of which have been reported to be present in exosomes derived from other cell types.

\section{Results}

Proteomic analysis of exosomes secreted by Wnt3a treated microglia

Tissue culture medium harvested from primary rat microglia treated with carrier-free Wnt3a (10 nM) and centrifuged at 100000xg contained proteins characteristic of exosomes as demonstrated by proteomic profiling (Table 1). Conversely, medium collected from control microglia and centrifuged at 100000xg was completely devoid of any detectable protein as shown by coomassie staining of one dimensional SDS-PAGE gels (Figure 1). The concentration of exosomal proteins present in the extracellular fluid represents approximately $0.5 \%$ of total cellular protein. The concentration of Wnt3a used (10 $\mathrm{nM}$ ) caused a robust activation of TOPflash, a reporter gene construct containing tandem repeats of optimal

\section{$100000 \times$ fraction}

\section{MW kD Control Wnt3a}

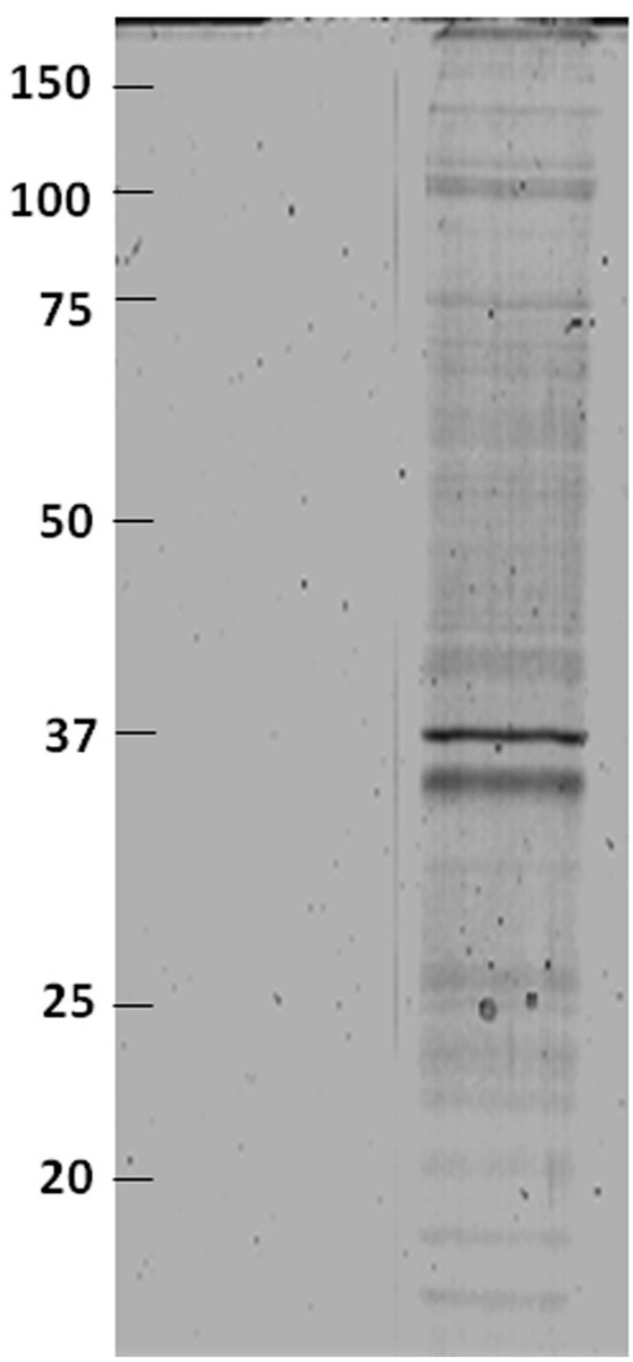

Figure 1 Coomassie stained gel of proteins isolated from exosomal fractions derived from primary microglia. Primary microglia (2500000 cells) were treated with or without Wnt3a $(10 \mathrm{nM})$ for 8 hours in SFM. Cell culture medium was collected, centrifuged at $10000 \mathrm{xg}$ for 10 minutes, concentrated using 3kDa centrifugal devices and exosomes were isolated at 100000xg. Proteins were separated by SDS-PAGE and visualised using coomassie blue. 
TCF/LEF binding sites $(22 \pm 1.2$ fold increase over control), indicating that the recombinant Wnt3a protein was active and able to signal through the $\beta$-catenin/ GSK3 dependent pathway. Lot to lot variability in the ability of Wnt3a to induce exosome secretion was not observed as has been documented for other Wnt3a induced signaling events [21]. Western blotting corroborated proteomic findings showing that the 100000xg exosomal fraction contained Wnt3a and $\beta$-actin (Figure 2A). Smaller vesicles were also isolated by a subsequent centrifugation step at 200000xg. Western blotting demonstrated the presence of Wnt3a, $\beta$-actin and apoptosis-linked gene 2 -interacting protein (Alix) in the $200000 x g$ fraction (Figure 2A). In contrast, Alix was not detectable in the 100000xg exosomal fraction 8 hours post Wnt3a stimulation. However, 36 hours post Wnt3a treatment Alix could be detected by western blotting in the $100000 x g$ fraction when the number of donor microglia was increased 5 fold (Figure 2B).

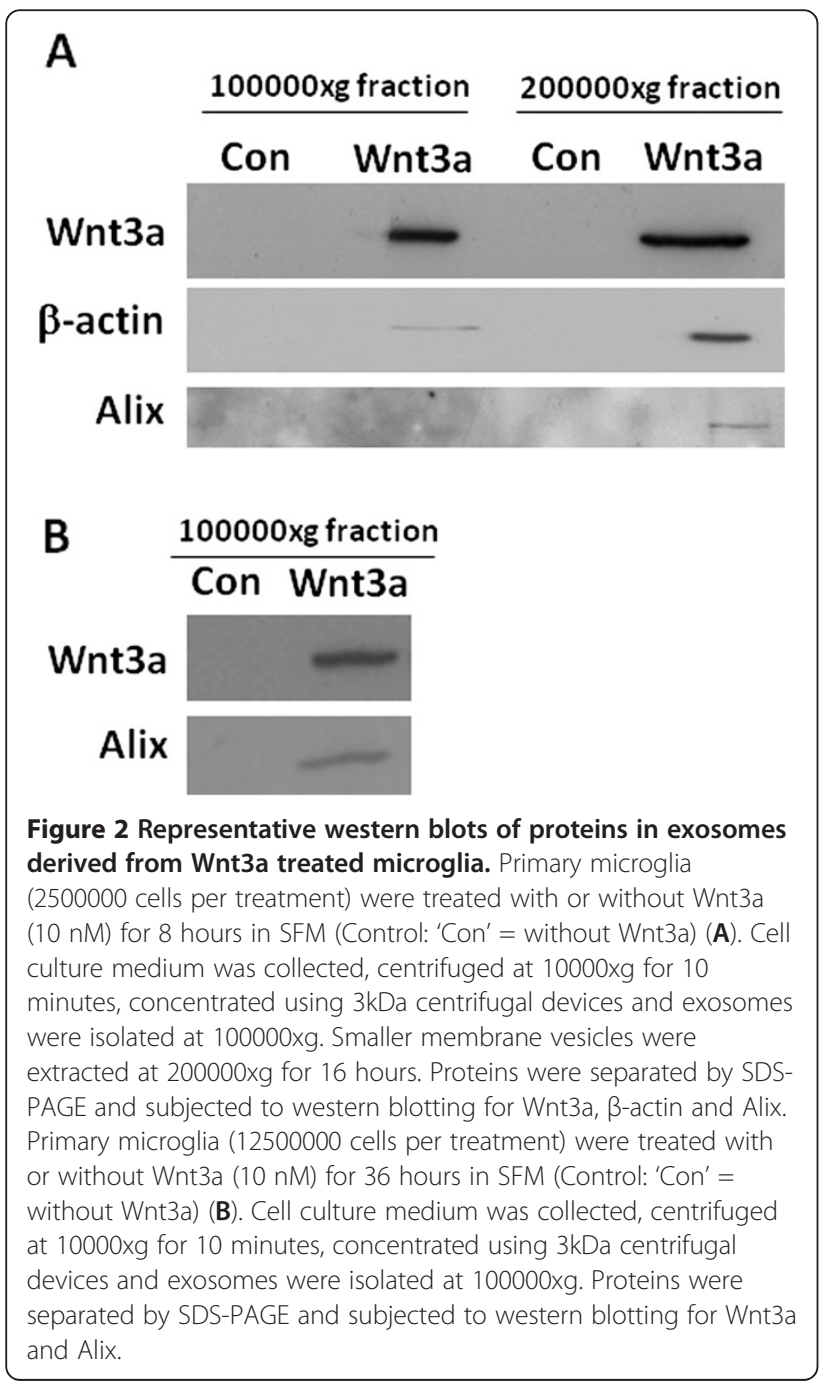

Neither Wnt5a or Wnt5b (at concentrations of 10 $500 \mathrm{nM}$ ) caused the release of lipid-bound vesicles from microglia, 8 hours post treatment, as demonstrated by two dimensional gel electrophoresis (2DGE) followed by silver staining. Silver staining provides a more sensitive method for the detection of protein than staining with coomassie blue (Figure 3). Furthermore, other modulators of GSK3 activity, used at physiologically relevant concentrations, including lithium (5 mM), insulin (100 $\mathrm{nM})$, DKK1 (30 nM), sonic hedgehog (500 nM) or reelin (50 nM: active signaling fragment containing amino acids 1221-2661) did not elicit exosome release or the release of smaller lipid-bound vesicles from microglia (data not shown).

\section{Effects of Wnt3a on the inflammatory profile of microglia} Control microglia or microglia treated with Wnt3a for 8 (Figure 4A) or 24 hours (Figure $4 \mathrm{~B}$ ) did not secrete GMCSF, IFN- $\gamma$, IL1 $\alpha$, IL1 $\beta$, IL2, IL4, IL6, IL10, IL12 or TNF $\alpha$. In contrast, LPS $(10 \mathrm{ng} / \mathrm{ml})$ treated microglia secreted TNF $\alpha$ and IL1 $\beta$, the archetypal pro-inflammatory cytokines, at both of these time points. Wnt3a treated microglia did not express inducible nitric oxide synthase (iNOS) after 24 hours in culture as demonstrated by Western blotting, whilst LPS $(10 \mathrm{ng} / \mathrm{ml})$ treated microglia did express this enzyme (Figure 4C). Conditioned medium collected from Wnt3a treated microglia did not possess significant neurotoxic properties as demonstrated by MTT and LDH assay (Figure 5). In contrast, conditioned medium collected from LPS $(10 \mathrm{ng} / \mathrm{ml})$, oligomeric A $\beta$ $(3 \mu \mathrm{M})$ or oligomeric $\alpha$-synuclein $(500 \mathrm{nM})$ treated microglia was neurotoxic, which is consistent with previously published findings [22,23]. LPS and oligomeric $\alpha$-synuclein caused marginal, but non-significant, neuronal death when added to cortical neuron cultures with control microglial conditioned medium. The addition of oligomeric $\mathrm{A} \beta$ in conjunction with control microglial conditioned medium to neurons evoked significant albeit comparatively low levels of death after 24 hours in culture. Interestingly, conditioned medium collected from Wnt3a treated microglia was slightly protective against neuronal death induced by medium collected from microglia treated with LPS $(10 \mathrm{ng} / \mathrm{ml})$, oligomeric $\mathrm{A} \beta(3 \mu \mathrm{M})$ or oligomeric $\alpha$-synuclein $(500 \mathrm{nM})$, although the results were not statistically significant. Collectively, these findings suggest that Wnt3a treated microglia do not exhibit a typical pro-inflammatory phenotype; in fact they might confer a small level of neuro-protection.

\section{Visualisation of microglial-derived exosomes induced by Wnt3a treatment}

Electron microscopy corroborated proteomic data and demonstrated that Wnt3a $(10 \mathrm{nM})$ treated microglia released exosomes that were electron-dense and approximately 
Figure $3 \mathrm{Wnt5a}$ and $\mathrm{Wnt} 5 \mathrm{~b}$ fail to induce exosomes release from microglia as demonstrated by 2DGE. Primary microglia (2500000 cells) were either left untreated (Control) or treated with Wnt3a (10 nM), Wnt5a (500 nM) or Wnt5b (500 nM) in SFM for 8 hours in SFM. Cell culture medium was collected, centrifuged at 10000xg for 10 minutes, concentrated using 3kDa centrifugal devices and exosomes were then isolated at 100000xg. Proteins were separated by 2DGE and visualised using silver staining.

$100 \mathrm{~nm}$ in diameter, typical of exosomal size; 40-100 $\mathrm{nm}$ (Figure 6). Microglial-derived exosomes aggregated in vitro and labelled positively with $\beta$-actin (Figure 6A) and Wnt3a (Figure 6B), which illustrates their biological nature. Freshly isolated exosomes were more disperse and osmium tetroxide staining revealed an elliptical structure enclosed by a lipid-bilayer (Figure 6C).

Double immuno-fluorescent staining in N9 microglial cells demonstrated the presence of Wnt3a in early endosomes, 2 hours post treatment, with Wnt3a co-localising with the endosomal marker Rab5. This indicates that Wnt3a is endocytosed before being directed into exosomes for secretion (Figure 7). Single staining for Wnt3a or Rab5 independently produced similar staining patterns (data not shown).

\section{Wnt3a does not induce nuclear pyknosis or compromise cell membrane integrity}

Microglial cells treated with Wnt3a $(10 \mathrm{nM})$ for 24 hours possessed large healthy nuclei, identical in appearance and number to control cells, as demonstrated by Hoechst 33342 staining (Figure 8A, B and C). Moreover, exosomes do not contain the pro-apoptotic protein cytochrome $\mathrm{c}$ as shown by LC/MS/MS (see Table 1). These findings indicate that Wnt3a treatment does not trigger apoptosis and thus it is inferred that membrane blebbing is not elicited, which is a terminal event in the apoptotic pathway. Therefore, apoptotic bodies most likely do not account for the presence of the extracellular vesicles identified in this study. Furthermore, fluoroscein diacetate staining revealed that microglial cultures treated with Wnt3a $(10 \mathrm{nM})$ for 24 hours comprised a similar number of fluorescent cells as untreated control cultures (Figure 8D, E and F). Fluoroscein diacetate is metabolised and retained by healthy cells comprising an intact plasma membrane resulting in the visualisation of an intracellular green fluorescent product. This fluorescent dye therefore provides a measure of cell membrane integrity. Thus, these results indicate that the microglial cells are intact and cellular contents/organelles are retained inside the microglial cells following exposure to Wnt3a and most likely do not contaminate the exosomal fraction. 


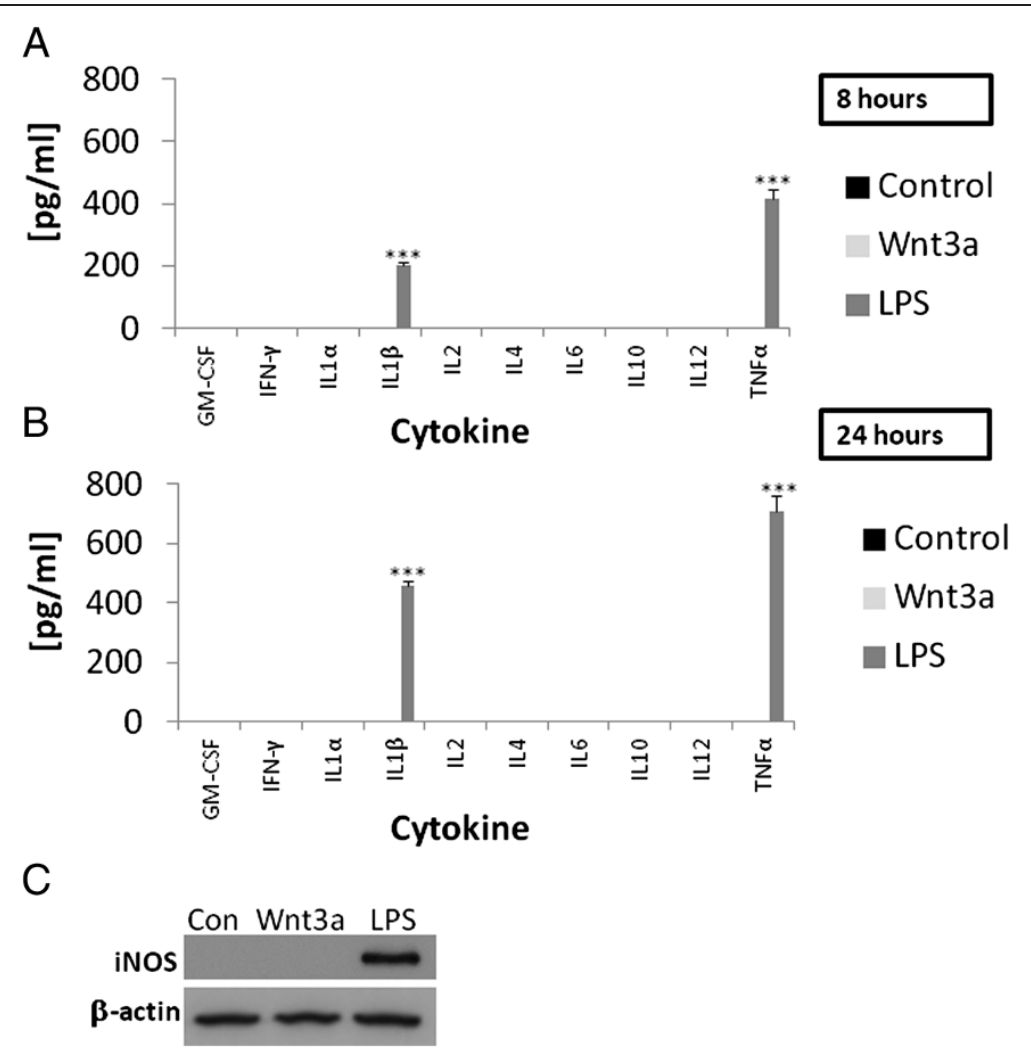

Figure 4 Assessment of the inflammatory properties of Wnt3a in microglia. Microglia (1 million cells per treatment) were treated with either Wnt3a (10 nM) or LPS (10 ng/ml) for 8 (A) or 24 hours (B) in SFM at $37^{\circ} \mathrm{C}$. Control cultures were left in SFM for the corresponding time points. Cell culture supernatants were then collected and analysed for the presence of cytokines using a 10-plex immuno-fluorescent assay. Microglia (250000 cells per treatment) were treated with either Wnt3a $(10 \mathrm{nM})$ or LPS $(10 \mathrm{ng} / \mathrm{ml})$ for 24 hours and then subjected to western blotting for iNOS and $\beta$-actin (C). Control microglia were cultured in SFM for 24 hours. ${ }^{* *} p<0.001$.

\section{Effects of Wnt3a on neuronal-derived exosomes}

Primary cultured rat cortical neurons released exosomes constitutively and Wnt3a (10 nM) treatment did not alter exosome secretion as measured in terms of total exosomal protein and the observable banding patterns visible upon coomassie staining (Figure 9A). As was the case with microglia, Wnt3a was detectable in neuronalderived exosomes collected from Wnt3a (10 nM) treated cortical neurons (Figure 9B). This suggests that Wnt3a is endocytosed and packaged into exosomes subcellularly as is the case with microglia. Exosomes derived from cortical neurons also contained, Alix, the archetypal exosomal marker, as shown by western blotting (Figure 9B).

\section{Wnt3a does not bind non-specifically to the external surface of exosomal membranes}

To provide further evidence that Wnt3a traverses the cell through the endocytic route and does not nonspecifically associate with the external surface of exosomal membranes; exosomes were incubated with Wnt3a in a cell free environment and the presence of Wnt in the exosomal fraction was tested. Cortical neurons were used to provide a source of exosomes due to the constitutive nature of their release from this cell type. Exosomes isolated from 2.5 million cortical neurons were incubated with Wnt3a $(10 \mathrm{nM})$ for 8 hours. The exosomes were subsequently pelleted by centrifugation at 100000xg and the exosomal fraction and the supernatant were western blotted for the presence of Wnt3a (Figure 10). Wnt3a was only present in the supernatant. This suggests that Wnt3a does not attach nonspecifically to the external surface of the exosomal membranes; a phenomenon that could potentially occur through the hydrophobic lipid modifications that are present on Wnt $[24,25]$.

\section{Wnt3a- induced exosome secretion from microglia is independent of GSK3}

The naturally occurring Wnt antagonist DKK1 (30 nM) failed to inhibit Wnt3a-induced exosome release from microglia (Figure 11A). The same concentration of DKK1 (30 nM) caused the complete abatement of Wnt3a-induced TOPflash activity in HEK293a cells (Figure 11B). In fact, DKK1 potentiated Wnt3a-induced exosome release as measured by the presence of $\beta$-actin 


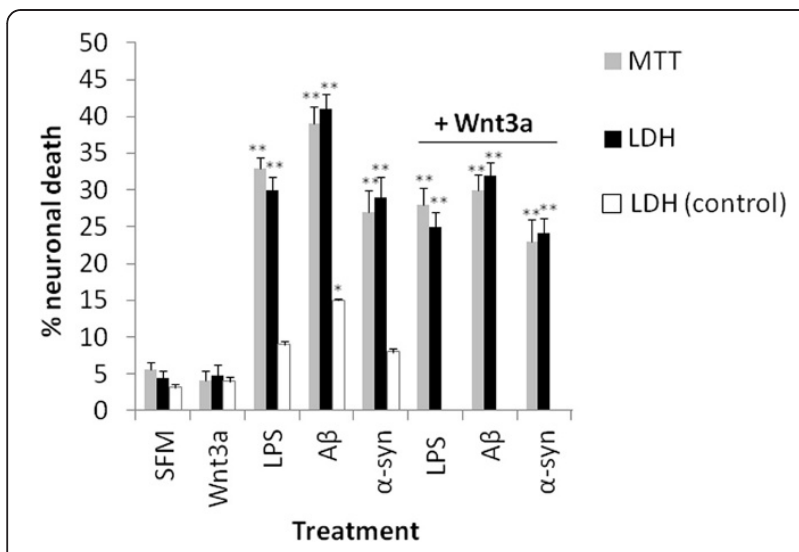

Figure 5 Assessment of the neurotoxic properties of Wnt3a treated microglia. Primary microglia (300000 cells per treatment) were treated with Wnt3a $(10 \mathrm{nM})$, LPS $(10 \mathrm{ng} / \mathrm{ml})$, oligomeric A $\beta$ $(3 \mu \mathrm{M})$ or oligomeric a-synuclein $(500 \mathrm{nM})$ for 24 hours and the medium was collected. Control medium was collected from untreated microglia in SFM (SFM). This medium was then added to cortical neuron cultures (500000 cells per treatment) for a further 24 hours before neurotoxicity assays were performed. Some neuronal cultures were exposed to conditioned medium collected from microglia treated with LPS $(10 \mathrm{ng} / \mathrm{ml})$, oligomeric $\mathrm{A} \beta(3 \mu \mathrm{M})$ or oligomeric a-synuclein $(500 \mathrm{nM})$ in the presence of medium collected from Wnt3a treated microglia (as indicated).

Neuronal death was assessed by MTT (grey bars) and LDH (black bars) assays. In addition, LPS (10 ng/ml), oligomeric $A \beta(3 \mu \mathrm{M})$ or oligomeric a-synuclein (500 nM) were directly added to neuronal cultures in the presence of conditioned medium collected from control microglia to account for any direct neurotoxic effects of the microglial activators and toxicity was assessed by LDH assay (white bars: LDH control). ${ }^{*} p<0.05,{ }^{* *} p<0.01$.

in the 100000xg fraction, which provides a surrogate measure for total exosomal protein. In contrast, DKK1 had no effect on exosome secretion when incubated with microglial cells alone. Inhibition of GSK3 using lithium (5 $\mu \mathrm{M})$, which mimics $\beta$-catenin/GSK3-dependent Wnt signaling, did not evoke exosome release or accentuate or attenuate Wnt3a-induced release (Figure 11A). Lithium $(5 \mu \mathrm{M})$ did however, activate TOPflash in HEK293a cells to a similar degree as Wnt3a (Figure 11B). Together these findings suggest that Wnt3a-induced exosome secretion occurs independently of GSK3 in microglia.

\section{Discussion}

Research into exosomal signaling in the CNS is scant especially with regard to glial cells. However, astrocytes and glioblastomas release exosomes containing mitochondrial DNA [26] and primary mouse microglia, BV2 microglial cells as well as the N9 microglial cell line have been reported to secrete exosomes constitutively [27-29]. We show here that primary rat microglia release exosomes following stimulation with Wnt3a, but exosomes or indeed other proteins are not released under control conditions in our study. This discrepancy with

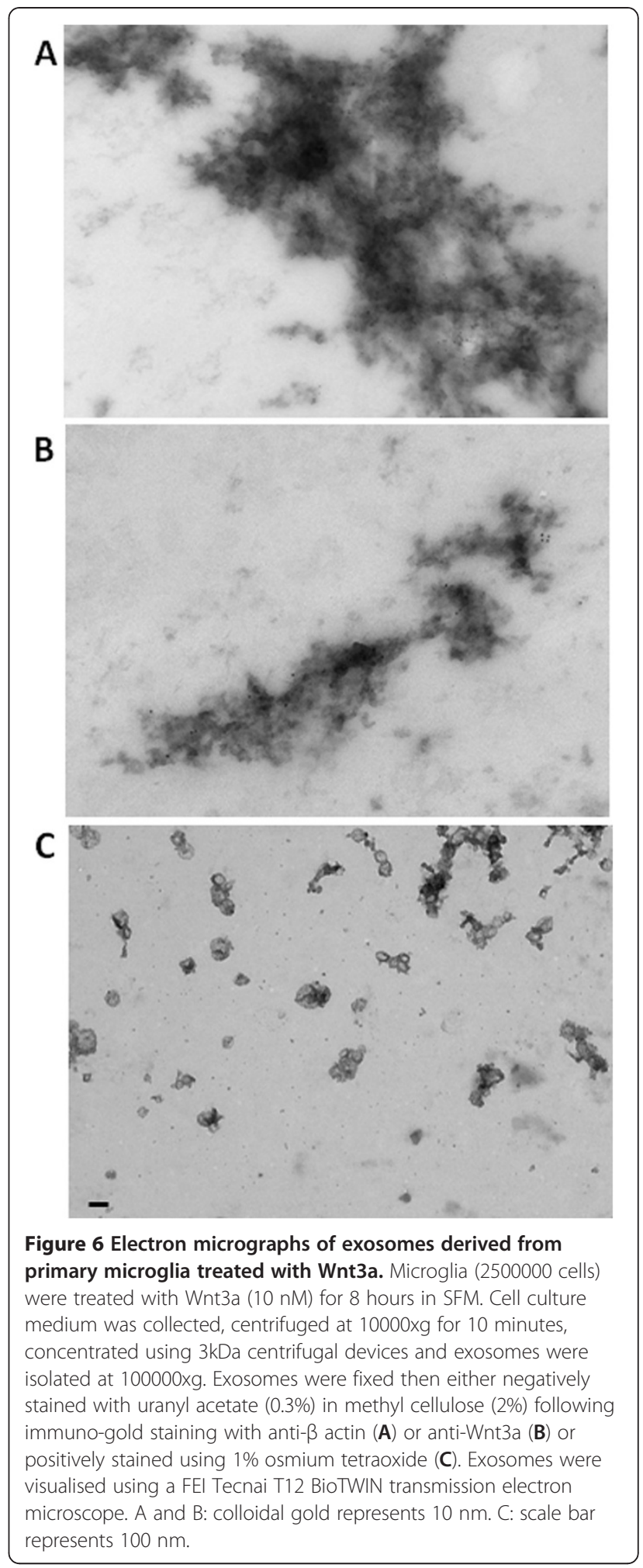

previous findings might reflect the down-regulated nature of our microglia isolated using percoll density gradient centrifugation compared to microglia isolated from mixed glial cultures, or microglial cell lines, which display 

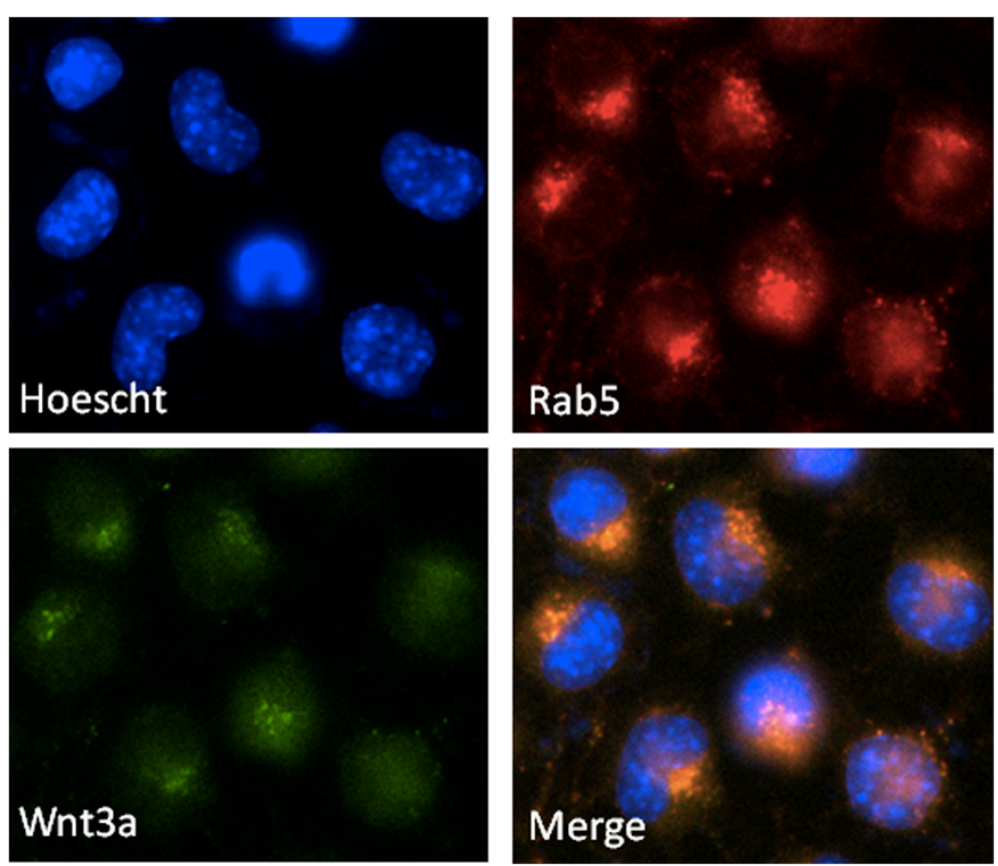

Figure 7 Wnt3a co-localises with early endosomes intracellularly in microglia. N9 microglia. (50000 cells per treatment/coverslip on the day of plating) were treated with Wnt3a (10 nM) for 2 hours then fixed and stained with rabbit anti-Wnt3a (1:500: green staining) and mouse antiRab5 (1:500: red staining) (A). Nuclei were counterstained with Hoechst 33342. Scale bar represents $10 \mu \mathrm{m}$.

a heighten activation state due to time spent in culture (unpublished observations: J Pocock). Wnt3a-induced exosomes were approximately $100 \mathrm{~nm}$ in diameter; typical of exosomal size. The vesicles aggregated in vitro and harboured immunoreactivity for Alix and $\beta$-actin and contained a number of other structural enzymes as demonstrated by LC/MS/MS. Wnt3a was found to be associated with exosomes both by electron microscopy and LC/MS/MS profiling. Furthermore, immuno-localisation with Rab5 suggests that Wnt3a is internalised into early endosomes before being released from the cell in exosomes. This is consistent with a study that shows that internalisation of Wnt is necessary for its signaling [30]. The mechanism involved in Wnt3a-induced exosome secretion remains to be determined, although the involvement of GSK3 was ruled out. Little is known about the regulation of multi-vesicular body fusion and exosome release, although calcium [31] and citron kinase (a RhoA effector) [32] have been implicated. Interestingly, DKK1 potentiated Wnt3a-induced exosomes secretion, whilst DKK1 challenge alone did not stimulate exosomes release. This corroborates the notion that Wnt3a is acting to elicit exosomes secretion through a pathway independent of GSK3/ $\beta$-catenin as blocking this pathway diverts Wnt3a to augment the activation of an alternate route. This is possible since DKK1 inhibits the GSK3/ $\beta$-catenin pathway not by preventing Wnt binding to Frizzled, but rather by blocking the interaction of Frizzled with the necessary co-receptors, LRP5/6.

Wnt3a treated microglia did not secrete cytokines or express iNOS and therefore by supposition the signaling molecule nitric oxide was not released. Furthermore, Wnt3a treated microglia did not possess neurotoxic properties. In fact, Wnt3a treated microglia conferred marginal protection against neuronal cell death elicited by microglia treated with $A \beta, \alpha$-synuclein or LPS. It has recently been reported that Wnt3a increases the expression of IL-6, IL-12, and TNF $\alpha$ in microglia [11]. However, the control cultures in the study reporting this were exposed to $1 \% \mathrm{BSA}$ and it is not stipulated whether the recombinant Wnt3a used was carrier-free. Carriers could potentiate any microglial response especially if the carrier is BSA $[33,34]$. In retinal cells activation of the $\beta$ catenin/GSK3 dependent Wnt pathway with Wnt3a is sufficient to induce inflammation characterised by vascular endothelial growth factor (VEGF) and TNF $\alpha$ secretion and the production of reactive oxygen species [35]. This suggests that Wnt signaling might act in a cell type specific manner with respect to inflammatory signaling depending on the receptor profile expressed on a particular population of cells.

Wnt3a associated with cortical neuron-derived exosomes following its prior addition to the extracellular milieu. However, Wnt3a did not modify exosome 

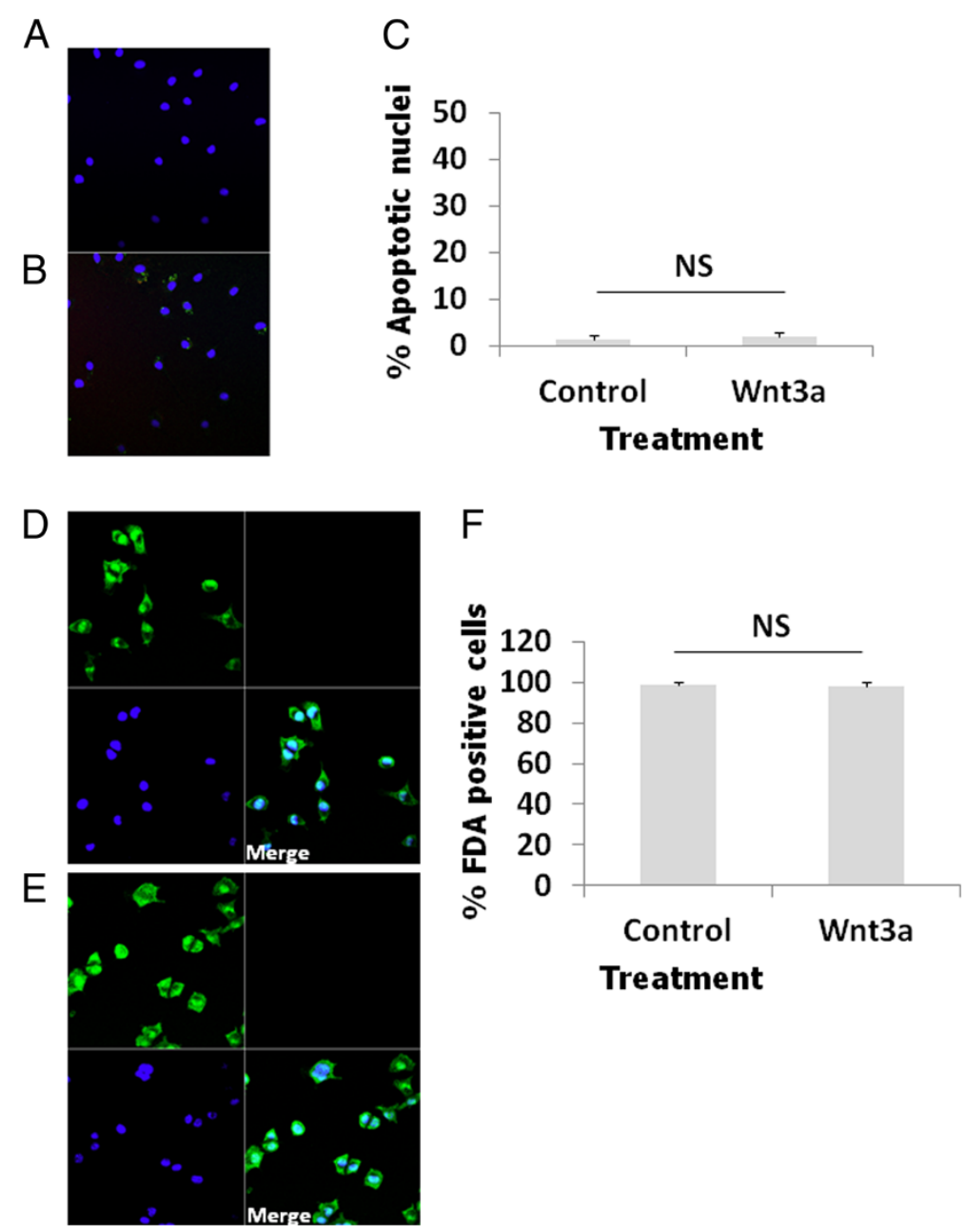

Figure $8 \mathrm{Wnt} 3 \mathrm{a}$ does not induce the formation of apoptotic nuclei in microglia or compromise cell membrane integrity. Apoptosis was assessed using Hoechst 33342. Microglia on $13 \mathrm{~mm}$ coverslips (50000 cells per treatment) were treated with (A) and without (B) Wnt3a (10 nM) for 24 hours then fixed in formaldehyde (4\%) and incubated with Hoechst $33342(17.8 \mu \mathrm{M})$. Apoptotic microglia were expressed as a percentage of the total number of cells counted per field (C). Treatments were deemed statistically non-significant (NS) according to a two tailed student's T-Test. Cell membrane integrity was assessed using fluoroscein diacetate (FDA). Microglia on $13 \mathrm{~mm}$ coverslips (50000 cells per treatment) were treated with (D) and without (E) Wnt3a (10 nM) for 24 hours then incubated with fluoroscein diacetate (35 $\mu \mathrm{M}$ : green staining) and Hoechst 33342 (17.8 $\mu \mathrm{M}$ : blue staining) to counter-stain cell nuclei. Fluoroscein diacetate positive cells were expressed as a percentage of the total number of cells counted per field (F). Treatments were deemed statistically non-significant (NS) according to a two tailed student's T-Test.

secretion over baseline in neurons in terms of total protein levels in the 100000xg fraction and in the appearance of observable bands apparent on coomassie-stained gels. However, for this to be verified absolutely further LC/MS/MS analysis would have to be performed. Exosomes derived from cortical neurons comprised a different protein profile to microglial-derived exosomes as illustrated by coomassie staining of the electrophoretically resolved exosomal proteomes. Nonetheless, cortical neurons have been reported to release exosomes containing $\beta$-tubulin, $\gamma$-actin, clathrin heavy chain, ubiquitin and metabolic enzymes such as pyruvate kinase and glyceraldehyde 3 phosphate dehydrogenase [36]; similar to those proteins found in the microglial derived exosomes described in this study. This suggests that a number of common proteins are found in exosomes originating from both cell types. In fact, the presence of metabolic enzymes in exosomes appears to be characteristic of such vesicles from a variety of cell types [37]. Heat shock proteins and annexins are also found in exosomes from a number of sources including keratinocytes and dendritic cells [38,39], which is consistent with our findings. Endosomal-lysosomal sorting proteins such as endosomal sorting complex required for transport (ESCRT), tumour susceptibility gene 101 (Tsg-101) and Alix as well as tetraspanins are characteristic of exosomes. However, not all exosomes express these markers [37]. Alix was detectable in exosomes derived from 


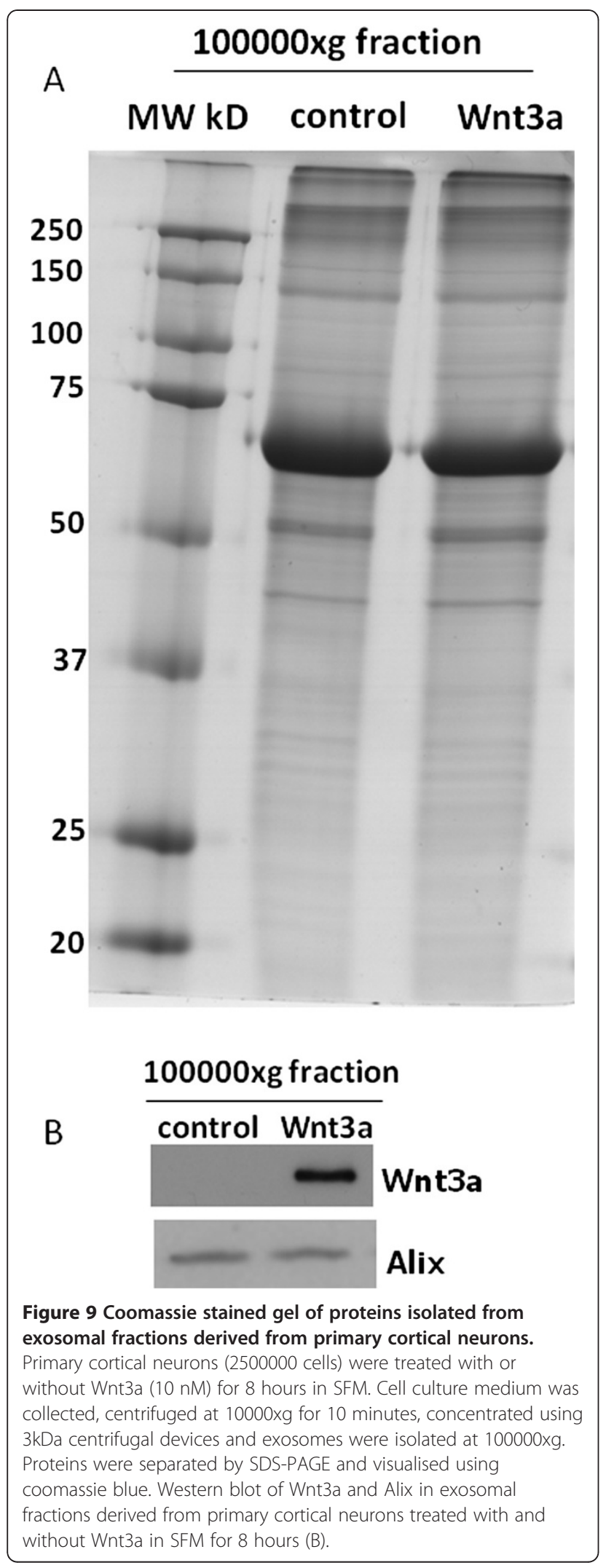

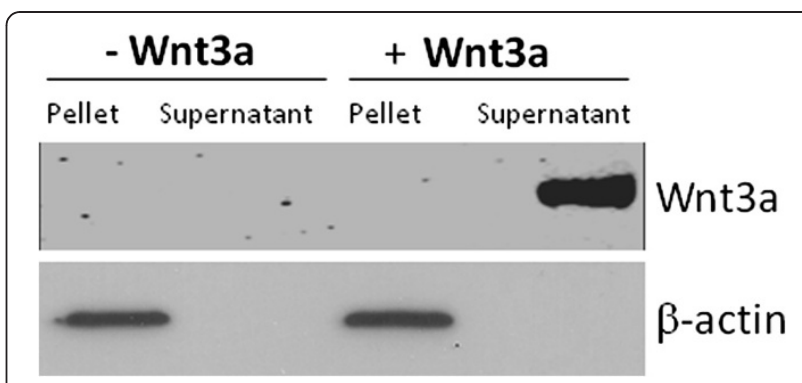

Figure 10 Assessment of non-specific binding of Wnt3a to exosomal membranes. Exosomes were isolated from primary cortical neurons (2500000 cells) and incubated with and without $( \pm)$ Wnt3a (10 nM) in a cell free environment (in SFM) for 8 hours. Following the incubation the exosomes were pelleted by centrifugation at $100000 \mathrm{xg}$ for 1 hour and the pellets and the supernatants were subjected to western blotting for the detection of Wnt3a and $\beta$-actin as an exosomal marker.

cortical neurons and in both the 100000xg and 200000xg vesicular fractions isolated from Wnt3a treated microglia.

The functional significance of Wnt3a induced exosome secretion from microglia remains to be determined. Neurons treated with exosomes derived from Wnt3a treated microglia did not display an altered protein expression pattern as demonstrated by 2DGE (data not shown). This implies that the exosomes do not signal to alter neuronal phenotype/function. However, the effects of exosomal cargo transfer might be so subtle that they are beyond the limits of detection by 2DGE. Exosomes are known to play a role in antigen presentation [40], so it is conceivable that Wnt-3a-induced exosome production might play a role in the central inflammatory response. Exosomes derived from Wnt3a treated microglia might also serve to create morphogen gradients during CNS development; certainly amoeboid microglia play a key role in developmental processes. In drosophila, Wingless (the fly homologue of mammalian Wnts) is found in multi-vesicular bodies and large intracellular vesicles as well as export vesicles known as argosomes [41,42]. Thus, Wingless/Wnt might be endocytosed and then passed from cell to cell via exosomelike vesicles to establish morphogen gradients. In addition or alternatively, Wnt3a-induced microglial derived exosomes might function as a clearance system for unwanted cellular proteins. Our proteomic data reveals the presence of ubiquitin and proteasomal subunits in microglial derived exosomes suggestive of a degradative role. Consistent with this, the tetraspanins, CD82 and CD9, possessing tumour supressor properties, down-regulate Wnt signaling through the exosomal discharge of $\beta$-catenin [43]. Of note, Sonic hedgehog, another modulator of GSK3 activity, when delivered using small membrane derived vesicles has been shown to promote angiogenesis in vascular endothelial cells, which 


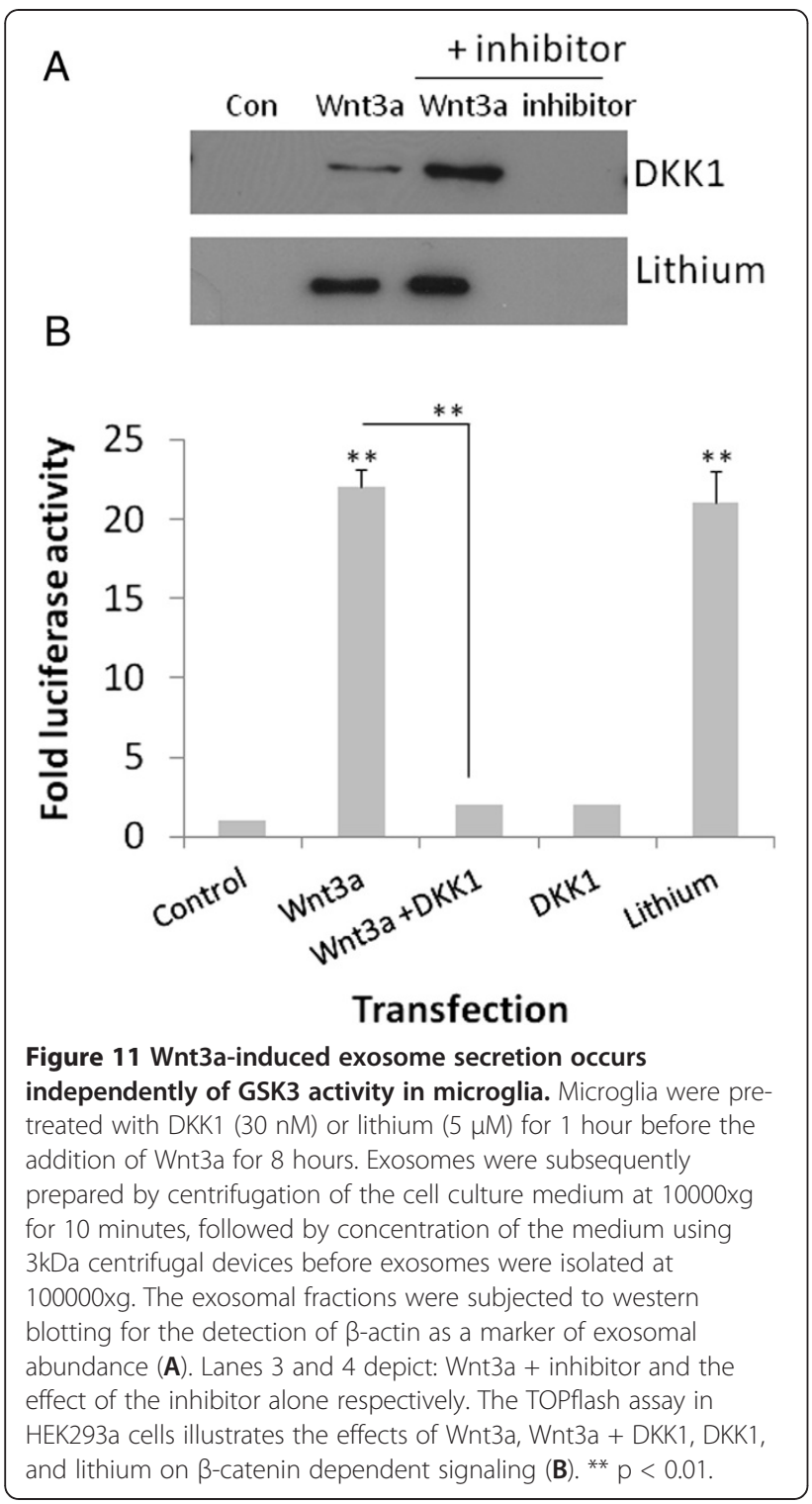

bears relevance for ischemic disease [44]. Indeed exosomes and other vesicular structures provide novel avenues for future therapies.

\section{Conclusion}

In summary, primary cultured rat microglia release electron dense exosomes after treatment with Wnt3a that are loaded with proteinaceous cargo including structural proteins, metabolic enzymes and proteins involved in both protein synthesis and degradation. These findings have implications for cellular cross-talk in the CNS, involving bulk transfer of material, in both health and disease.

\section{Methods}

\section{Materials}

Sprague dawley rats were bred and reared in house from stock animals obtained from Charles River UK Ltd (Margate, Kent, UK). Human embryonic kidney 293a cells (HEK293a; an adherent clone of HEK293 cells) were purchased from Quantum Biotechnologies (Canada). N9 microglial cells were a kind gift from Dr Paola Ricciardi Castagnoli (CNR Cellular and Molecular Pharmacology Centre, Milan, Italy). The TOPflash firefly-luciferase reporter construct was purchased from Millipore (Watford, UK). Fetal calf serum, Dulbeccos Modified Eagle Medium (DMEM), Neurobasal medium, B27 supplement and the rat cytokine 10-plex immunofluorescent assay panels (LRC0002) were obtained from Invitrogen (Paisley, UK). Papain digestion kits were from Lorne Labs (Berkshire, UK). Recombinant carrier-free mouse Wnt3a, Wnt5a, Wnt5b, dickkopf 1 (DKK1), reelin and sonic hedgehog were from R\&D Systems (Abingdon, UK). $\alpha$-synuclein was from Enzo Life Sciences (Exeter, UK). $\beta$-amyloid (1-42) was from Dr David Teplow (UCLA, California, USA). Recombinant insulin, percoll, lipopolysaccharide (LPS), Hoechst 33342, fluoroscein diacetate, mouse anti- $\beta$ actin and lithium were supplied by Sigma (Dorset, UK). FuGENE6 was from Roche (Burgess Hill, UK). Rabbit anti-Wnt3a and mouse anti-Alix were from Cell Signaling Technology (Hertfordshire, UK). Mouse anti-Rab5 was from Abcam (Cambridge, UK). Goat antimouse IgG-HRP and goat anti-rabbit IgG-HRP were from Autogen Bioclear (Wiltshire, UK). Anti-mouse and antirabbit IgG conjugated to $10 \mathrm{~nm}$ colloidal gold was from British Biocell (Cardiff UK). Enhanced chemiluminescence reagents were from GE Healthcare (Buckinghamshire, UK). C18 PepMap columns were from Dionex (Surrey, UK). Amicon centrifugal devices $(3 \mathrm{kDa})$ were from Fisher Scientific (Loughborough, UK). Immobiline Drystrips (pH 3-11) were from GE Healthcare (Buckinghamshire, UK). The 'Cell Titre 96 AQueous One Solution Proliferation Assay kit' (MTT assay) and the CytoTox $96^{\circledR}$ Non-Radioactive Cytotoxicity Assay kit (measures LDH') and Dual-Glo reagents were obtained from Promega (Southampton, UK). Pioloform and EM grids come from Agar Scientific (Stansted, UK).

\section{Aggregation of $\beta$-amyloid and a-synuclein}

$\beta$-amyloid 1-42 (A $\beta$ ) peptide was resuspended in 1,1,1,3,3,3 hexafluoro-2-propanol (HFIP: $1 \mathrm{mM}$ ) and homogenized using a Teflon plugged $(250 \mu \mathrm{l})$ Hamilton syringe. HFIP was removed by evaporation in a SpeedVac and $A \beta$ was resuspended at a concentration of 5 $\mathrm{mM}$ in dimethylsulfoxide (DMSO) and sonicated for 10 minutes. For oligomer formation, $\mathrm{A} \beta$ (1-42) was diluted 
to $0.4 \mathrm{mM}$ in phosphate buffered saline (PBS) plus $0.2 \%$ sodium dodecyl sulfate and incubated at $37^{\circ} \mathrm{C}$ for 24 hours then diluted to $100 \mu \mathrm{M}$ with PBS and incubated at $37^{\circ} \mathrm{C}$ for 18 hours before use [45]. $\alpha$-synuclein was resuspended in PBS at a concentration of $68 \mu \mathrm{M}$ and incubated for 7 days at $37^{\circ} \mathrm{C}$ [22].

\section{Primary microglial cell culture and treatment}

Primary cultures of microglia were prepared from the brains of P6 Sprague Dawley rats using percoll density gradients as previously described [34]. In line with the Animals Scientific Procedures Act (1986) UK, the animal procedures undertaken to produce microglial cultures fall under Schedule 1 and were approved by the local ethics committee at the Institute of Psychiatry. All animals used in this study were treated in accordance with standard guidelines for laboratory animal care. Microglia were maintained at $37^{\circ} \mathrm{C}$ in a humidified atmosphere of $5 \% \mathrm{CO}_{2}$ in air and were used after 1 day in vitro. Using this approach microglial cultures were > 98\% pure as demonstrated by $\mathrm{CD} 11 \mathrm{~b}$ reactivity and morphological criteria. Primary microglia were treated with Wnt3a (10 $\mathrm{nM}$ ), or other agents as stipulated in the text, in serum free medium (SFM) (Dulbeccos modified eagles medium: DMEM) for 8 or 24 hours. Control cultures were incubated in SFM for the corresponding period.

\section{Culture and treatment of primary cortical neurons}

Primary cortical neuronal cultures were prepared from Sprague Dawley rat embryos on embryonic day 18 using papain dissociation as previously described [46]. In line with the Animals Scientific Procedures Act (1986) UK; pregnant rats were killed by a Schedule 1 method prior to the Schedule 1 killing of embryos. These animal procedures were approved by the local ethics committee at the Institute of Psychiatry. Neurons were cultured in neurobasal medium supplemented with B27 for 7 days at $37^{\circ} \mathrm{C}$ in a humidified atmosphere of $5 \% \mathrm{CO}_{2}$ in air. Neuronal cultures were $>98 \%$ pure as demonstrated by morphological criteria and staining for glial fibrillary acidic protein (GFAP) and CD11b; markers of astrocytes and microglia respectively. Following 7 days in vitro, primary neurons were treated with Wnt3a (10 nM) in neurobasal medium (minus supplements) for 8 hours. Control cultures were incubated in neurobasal medium (minus supplements) for the corresponding period.

\section{Growth and maintenance of cell lines}

N9 microglia and HEK293a cells were maintained in DMEM supplemented with glutamine $(2 \mathrm{mM})$, foetal bovine serum $(10 \%)$, penicillin $(100 \mathrm{U} / \mathrm{ml})$ and streptomycin $(100 \mu \mathrm{g} / \mathrm{ml})$ in a humidified atmosphere of $5 \%$ $\mathrm{CO}_{2}$ in air. N9 cells were plated on $13 \mathrm{~mm}$ glass coverslips (50000 cells/coverslip) and HEK293a cells were plated in 48 well plates (40000 cells/well) the day before use.

\section{Luciferase TOPflash assays}

HEK293a cells were transfected with TOPflash (400 ng) using FuGENE6 ( $1 \mu \mathrm{l}$ in a volume of $35 \mu \mathrm{l}$ SFM). Wnt3a (10 nM), DKK1 (30 nM), lithium $(5 \mu \mathrm{M})$ or Wnt3a (10 $\mathrm{nM})$ plus DKK1 (30 nM) were added to the culture media 18 hours after transfection. After a further 6 hours at $37^{\circ} \mathrm{C}$ the medium was removed from the cells and the firefly activity was measured using Dual-Glo reagents in a Wallac Trilux 1450 Luminometer. Data for each set of four replica transfections was averaged, the control in each set normalized to 1 and data presented as fold increases over control. All experiments were performed in triplicate. To statistically compare treatments a one-way analysis of variance (ANOVA) was used in combination with a Tukey post-test. $\mathrm{P}$ values $<0.05$ were considered statistically significant.

\section{Exosome preparation}

Cell culture supernatant was typically harvested from 2.5 million cells (primary microglia or primary cortical neurones), unless otherwise stated, after 8 hours in culture and was centrifuged at $10000 x$ for 10 minutes to clear large debris. The supernatant was then concentrated using Amicon 3kDa centrifugal devices according to the manufacturer's instructions. The concentrated supernatant was subjected to centrifugation at $100000 \mathrm{xg}$ for 1 hour to isolate exosomes. In some experiments a further 200000xg centrifugation step was performed for 16 hours to extract smaller vesicular particles.

\section{Western blotting and coomassie gels}

Cells, exosomes or other vesicular particles were harvested in lysis buffer $(10 \mu \mathrm{l}: 20 \mathrm{mM}$ Tris-acetate, $1 \mathrm{mM}$ EDTA, $1 \mathrm{mM}$ EGTA, $10 \mathrm{mM}$ sodium $\beta$-glycerophosphate, $1 \mathrm{mM}$ sodium orthovanadate, 5\% glycerol, $1 \%$ Triton X-100, 0.27 M sucrose, $1 \mathrm{mM}$ benzamidine, $4 \mu \mathrm{g}$ / $\mathrm{ml}$ leupeptin, $0.1 \% \quad \beta$-mercaptoethanol, $\mathrm{pH}$ 7.4) then incubated on ice for 10 minutes. Protein concentrations were determined according to the method of Bradford and confirmed using a NanoDrop ${ }^{2000}$ at $280 \mathrm{~nm}$. Proteins (exosomal: $500 \mathrm{ng} /$ well, cellular: $20 \mu \mathrm{g} / \mathrm{well}$ ) were resolved by SDS-PAGE (10\%) then stained with coomassie blue for 2 hours or transferred on to Immobilon P-PVDF membranes for subsequent western blotting. Membranes were probed according to standard protocols. Briefly, membranes were incubated with either mouse anti- $\beta$-actin (1:1000), rabbit anti-Wnt3a $(1: 1000)$ or mouse anti-Alix (1:1000) for 2 hours at room temperature. Membranes were then incubated for 2 hours at room temperature with goat anti-mouse IgGHRP (1:1000) or goat anti-rabbit IgG-HRP (1:1000). 
Proteins of interest were detected using enhanced chemiluminescence reagents. In some instances to ensure equal protein loading membranes were reprobed using mouse anti- $\beta$-actin (1:1000). Western blots were performed in triplicate from 3 independent experiments; therefore the blots shown are representative of a single experiment.

\section{Two dimensional gel electrophoresis}

Exosomal proteins were isoelectro-focussed on immobilized $\mathrm{pH}$ (3-11), dry, gradient strips using an Ettan IPGphor 3 system. Proteins were subsequently separated by SDS-PAGE (10\%) using an Ettan DALTtwelve large vertical two-dimensional gel tank in running buffer $(25 \mathrm{mM}$ Tris, $192 \mathrm{mM}$ glycine, $0.1 \%$ SDS). Gels were fixed in strong fix (40\% ethanol, $10 \%$ glacial acetic acid) for 1 hour and then in weak fix (5\% ethanol, 5\% glacial acetic acid) for 16 hours before proteins were visualized using silver staining. Two-dimensional gels were performed in triplicate from 3 independent experiments; therefore the images shown are representative of a single experiment.

\section{Liquid chromatography-tandem mass spectrometry (LC/ MS/MS)}

Exosomal proteins were separated by SDS-PAGE (10\%) and visualised with coomassie blue. In-gel reduction, alkylation and digestion (with trypsin) was subsequently performed. Peptides were extracted from the gel by a series of acetonitrile and aqueous washes and lyophilised. Each sample was then resuspended in ammonium bicarbonate $(50 \mathrm{mM})$ and analysed by LC/MS/MS. Chromatographic separations were performed using an Ultimate LC system (Dionex, UK). Peptides were resolved by reversed phase chromatography on a $75 \mu \mathrm{m}$ C18 PepMap column using a three step linear gradient of acetonitrile in formic acid $(0.05 \%)$. The gradient was delivered to elute the peptides at a flow rate of $200 \mathrm{~nL} /$ minute over 60 minutes. The eluate was ionised by electrospray ionisation using a Z-spray source fitted to a QTof-micro operating under MassLynx v4.0. The instrument was run in automated data-dependent switching mode, selecting precursor ions based on their intensity for sequencing by collision-induced fragmentation. The MS/MS analyses were conducted using collision energy profiles that were chosen based on the mass-to-charge ratio $(\mathrm{m} / \mathrm{z})$ and the charge state of the peptide. Database searching was carried out using MASCOT 2.2. All peptide assignments were manually validated.

\section{Assessment of cytokine secretion using a rat cytokine 10-plex immuno-fluorescent assay}

Microglia ( 1 million cells per treatment) were treated with either Wnt3a $(10 \mathrm{nM})$ or LPS $(10 \mathrm{ng} / \mathrm{ml})$ for 8 or 24 hours in SFM at $37^{\circ} \mathrm{C}$. Control cultures were left in
SFM for the corresponding time points. Cell culture supernatants were then collected and analysed simultaneously for the presence of cytokines (GM-CSF, IFN- $\gamma$, IL1 $\alpha$. IL1 $\beta$, IL2, IL4, IL6, IL10, IL12 and TNF $\alpha$ ) according to the manufacturer's instructions and fluorescence was quantified against standards using a Luminex ${ }^{200}$ instrument. All experiments were performed in triplicate. To statistically compare treatments an ANOVA was used in combination with a Tukey post-test. P values < 0.05 were considered statistically significant.

\section{Cell titre 96 AQueous one solution proliferation assay (MTT assay)}

Primary microglia (300000 cells per treatment) were treated with Wnt3a (10 nM), LPS (10 ng/ml), oligomeric $\mathrm{A} \beta(3 \mu \mathrm{M})$ or oligomeric $\alpha$-synuclein $(500 \mathrm{nM})$ for 24 hours and the medium (SFM) was collected. Control medium was collected from untreated microglia. This medium was then added to cortical neuron cultures (500000 cells per treatment) for a further 24 hours before the assay was performed. Some neuronal cultures were exposed to conditioned medium collected from microglia treated with LPS $(10 \mathrm{ng} / \mathrm{ml}), \mathrm{A} \beta(3 \mu \mathrm{M})$ or $\alpha-$ synuclein $(500 \mathrm{nM})$ in the presence of medium collected from Wnt3a treated microglia. The assay principle is that MTS [3-(4,5-dimethylthiazol-z-yl)-S-(3-carboxymethoxyphenyl)-2-(4-sulfophenyl-2H-tetrazolium)], a tetrazolium compound, is bioreduced by cellular NADP/NADPH to a coloured formazan end-product, which is soluble in tissue culture medium. Following treatment with conditioned medium, neurons (in $250 \mu \mathrm{l}$ of medium) were incubated with the Cell Titre 96 AQueous One Solution reagent (50 $\mu \mathrm{l})$, containing MTS, for 4 hours and the absorbance was subsequently read at $492 \mathrm{~nm}$ using a 96-well Anthos HTll microplate absorption photometer. Neurons were lysed with triton- X100 $(9 \% \mathrm{v} / \mathrm{v})$ as a positive control $(100 \%$ death) and neuronal death was calculated as a percentage of this total. All experiments were performed in triplicate. To statistically compare treatments an ANOVA was used in combination with a Tukey post-test. $\mathrm{P}$ values $<0.05$ were considered statistically significant.

\section{Cytotox $96^{\circledR}$ non-radioactive cytotoxicity assay kit (LDH assay)}

Cells were treated as described for the performance of the MTT assay above. In addition, LPS $(10 \mathrm{ng} / \mathrm{ml})$, oligomeric $\mathrm{A} \beta(3 \mu \mathrm{M})$ or oligomeric $\alpha$-synuclein $(500 \mathrm{nM})$ were directly added to neuronal cultures in the presence of conditioned medium collected from control microglia to account for any direct neurotoxic effects of the microglial activators. The assay measures lactate dehydrogenase (LDH), a cytoplasmic enzyme, released from the cell upon death. The assay is based on the formation of NADH from $\mathrm{NAD}^{+}$and lactate, which in turn reduces a tetrazolium 
compound into a coloured formazan end-product. In brief, medium was collected from neurons $(50 \mu \mathrm{l})$ and added to assay substrate mix $(50 \mu \mathrm{l})$ and incubated in that dark for 30 minutes at room temperature. Subsequently, stop solution $(50 \mu \mathrm{l})$ was added and the absorbance was read at 490nm. Neurons were lysed with triton- X100 $(9 \% \mathrm{v} / \mathrm{v})$ as a positive control (100\% death) and neuronal death was calculated as a percentage of this total. All experiments were performed in triplicate. To statistically compare treatments an ANOVA was used in combination with a Tukey post-test. $\mathrm{P}$ values $<0.05$ were considered statistically significant.

\section{Hoechst 33342 staining for nuclear morphology}

Primary microglial cells (50000 cells per treatment) were treated with and without Wnt3a (10 nM) for 24 hours. Apoptosis was subsequently assessed using the fluorescent dye 2'[epoxyphenyl]-5-[4-methyl-1-piperazinyl]2,5'-bi-1H-benzimidazol (Hoechst 33342) [47]. Microglia on $13 \mathrm{~mm}$ coverslips (50000 cell per treatment) were fixed in formaldehyde (4\%) in phosphate buffered saline at $4^{\circ} \mathrm{C}$, then incubated with Hoechst $33342(17.8 \mu \mathrm{M})$ for 10 minutes at $20^{\circ} \mathrm{C}$. Immunofluorescence was visualised and captured using a Zeiss Axioscope microscope and nuclear morphology was appraised at $365 \mathrm{~nm}$ with emission greater than $490 \mathrm{~nm}$ collected. Apoptotic cells possess brightly stained pyknotic nuclei, whereas, non apoptotic cells possess large weakly stained nuclei. Apoptotic cells were counted on three coverslips per treatment on three independent occasions (each coverslip comprised 10 fields of view). Apoptotic cells were expressed as a percentage of the total number of cells counted per field.

Fluoroscein diacetate staining for cell membrane integrity Primary microglial cells (50000 cells per treatment) were treated with and without Wnt3a (10 nM) for 24 hours. Cell membrane integrity was subsequently assessed using fluoroscein diacetate [47]. Primary microglial cells on coverslips were incubated with fluoroscein diacetate $(35 \mu \mathrm{M})$ for 10 minutes at $37^{\circ} \mathrm{C}$ in the dark. Cell viability was then assessed at $380 \mathrm{~nm}$ with emission greater than $505 \mathrm{~nm}$ collected. Fluoroscein diacetate is metabolised in healthy cells to form a fluorescent product, which emits at $530 \mathrm{~nm}$, staining live cells green. Fluorescent cells were counted on three coverslips per treatment on three independent occasions (each coverslip comprised 10 fields of view) and cells were expressed as a percentage of the total number of cells counted per field.

\section{Electron microscopy}

Exosomes suspended in phosphate buffered saline (PBS: $10 \mu \mathrm{l}$ ) were fixed by the addition of $16 \%$ formaldehyde $(1 \mu \mathrm{l})$. The exosomal solution $(3 \mu \mathrm{l})$ was then pipetted on to Pioloform coated electron microscopy grids. Excess fixative was quenched by exposing the grids to quenching buffer (PBS, $50 \mathrm{mM}$ glycine, $0.01 \%$ triton). Non-specific binding was minimised by blocking the grids in blocking buffer (PBS, $0.01 \%$ triton $0.1 \%$ acetylated BSA). The grids were then incubated with mouse anti- $\beta$-actin (1:1000) or rabbit anti-Wnt3a (1:1000) for 1 hour at room temperature in blocking buffer and washed in 6 changes of blocking buffer. The grids were subsequently incubated with anti-mouse or anti-rabbit IgG conjugated to $10 \mathrm{~nm}$ colloidal gold (1:100) for one hour at room temperature before being washed with 4 changes of PBS. The exosomes were then fixed in glutaraldehyde (2\%) and washed in 3 changes of distilled water before being contrasted with a mixture consisting of 9 parts uranyl acetate $(0.3 \%)$ to 1 part methyl cellulose (2\%). In other experiments, exosomes were fixed in glutaraldehye (2\%) then washed in 3 changes of distilled water before being stained with osmium tetroxide (1\%). Exosomes were visualised using a FEI Tecnai T12 BioTWIN transmission electron microscope fitted with an AMT camera. Exosomes were stained in triplicate from 3 independent experiments; therefore images are representative of a single experiment.

\section{Immunocytochemistry}

N9 microglia (50000 cells per treatment/coverslip on the day of plating) were treated with or without Wnt3a (10 $\mathrm{nM}$ ) for 2 hours then fixed with methanol at $4^{\circ} \mathrm{C}$ for 5 minutes. Cells were washed in three changes of PBS and then stained according to standard protocols. Briefly, cells were incubated with rabbit anti-Wnt3a (1:500) and/ or mouse anti-Rab5 (1:500) before being incubated with the appropriate fluorescent secondary antibody (1:500). Nuclei were counter-stained with Hoescht 33342. Immunofluorescence was visualized and captured using a Zeiss Axioscope microscope. All experiments were performed in triplicate. Figures shown are representative of a single experiment.

\section{Competing interests}

The authors declare that they have no competing interest.

\section{Authors' contributions}

$\mathrm{CH}$ - cell culture, exosomal preparation, TOPflash assay, western blotting, Hoechst 33342 staining, MTT and LDH assays. RSF - coomassie gels. SL - LC/ MS/MS. AH - cytokine quantification. AW - electron microscopy. RK immunocytochemistry for Wnt3a and Rab5. CB - cytokine quantification. JP supervision, immunocytochemisry and manuscript preparation. SL supervision and manuscript preparation. All authors read and approved the final manuscript.

\section{Acknowledgements}

This work was supported by the Alzheimer's Society (Claudie Hooper) and the MRC (Ricardo Sainz-Fuertes).

\section{Author details}

${ }^{1}$ King's College London, MRC Centre for Neurodegenerative Research, Institute of Psychiatry, De Crespigny Park, Denmark Hill, London SE5 8AF, UK. 
${ }^{2}$ Centre for Ultrastructural Imaging, King's College London, New Hunts House, Guy's Campus, London SE1 1UL, UK. ${ }^{3}$ Cell Signalling laboratory, Institute of Neurology, University College London, 1 Wakefield Street, London WC1N 1PJ, UK.

Received: 22 April 2012 Accepted: 12 October 2012 Published: 23 November 2012

\section{References}

1. Fetler L, Amigorena S: NEUROSCIENCE: brain under surveillance: the microglia patrol. Science 2005, 309:392-393.

2. Kreutzberg GW: Microglia: a sensor for pathological events in the CNS. Trends Neurosci 1996, 19:312-318.

3. Hooper C, Killick R, Lovestone S: The GSK3 hypothesis of Alzheimer's disease. J Neurochem 2007, 104:1433-1439.

4. Mudher A, Chapman S, Richardson J, Asuni A, Gibb G, Pollard C, Killick R, Iabal T, Raymond L, Varndell I, Sheppard P, Makoff A, Gower E, Soden PE, Lewis P, Murphy M, Golde TE, Rupniak HT, Anderton BH, Lovestone S: Dishevelled regulates the metabolism of amyloid precursor protein via protein kinase $\mathrm{C} /$ mitogen-activated protein kinase and c-Jun terminal kinase. J Neurosci 2001, 21:4987-4995.

5. Miller JR: The wnts. Genome Biol 2002, 3:REVIEWS3001.

6. Inestrosa NC, Arenas E: Emerging roles of wnts in the adult nervous system. Nat Rev Neurosci 2010, 11:77-86.

7. Kilander MB, Halleskog C, Schulte G: Recombinant wnts activate $\beta$-catenindependent and independent signaling in mouse microglia-like cells. Acta Physiol 2011, 203:363-372.

8. Macdonald BT, Semenov MV, He X: SnapShot: Wnt/beta catenin signalling. Cell 2007, 131:1204.

9. Semenov MV, Habas R, Macdonald BT, He X: SnapShot: noncanonical wnt signaling pathways. Cell 2007, 131:1378.

10. Hendrickx M, Leyns L: Non-conventional frizzled ligands and wnt receptors. Dev Growth Differ 2008, 50:229-243.

11. Halleskog C, Mulder J, Dahlstrom J, MAcjie K, Hortobagyi T, Tanila H, Kumar Puli L, Farber K, Harkany T, Schulte G: Wnt siganlling in activated microglia is pro-inflammatory. Glia 2011, 59:119-131.

12. Kohn AD, Moon RT: Wnt and calcium signaling: beta-cateninindependent pathways. Cell Calcium 2005, 38:439-446.

13. Thery C, Ostrowski M, Segura E: Membrane vesicles as conveyors of immune responses. Nat Rev Immunol 2009, 9:581-593.

14. Vella LJ, Greenwood DLV, Cappai R, Scheerlinck JP, Hill AF: Enrichment of prion protein in exosomes derived from ovine cerebral spinal fluid. Vet Immunol Immunopathol 2008, 124:385-393.

15. Camussi G, Deregibus MC, Bruno S, Cantaluppi V, Biancone L: Exosomes/ microvesicles as a mechanism of cell-to-cell communication. Kidney Int 2010, 78:838-848.

16. Keller S, Sanderson MP, Stoeck A, Altevogt P: Exosomes: from biogenesis and secretion to biological function. Immunol Lett 2006, 107:102-108.

17. Rajendran L, Honsho M, Zahn TR, Keller P, Geiger KD, Verkade P, Simons K: Alzheimer's disease +1-amyloid peptides are released in association with exosomes. Proc Natl Acad Sci 2006, 103:11172-11177.

18. Bulloj A, Leal MC, Xu H, Castano EM, Morelli L: Insulin-degrading enzyme sorting in exosomes: a secretory pathway for a key brain amyloid-beta degrading protease. J Alzheimers Dis 2010, 19:79-95.

19. Emmanouilidou E, Melachroinou K1, Roumeliotis T, Garbis SD, Ntzouni M, Margaritis $L H$, Stefanis $L$, Vekrellis $K$ : Cell-produced \{alpha\}-synuclein is secreted in a calcium-dependent manner by exosomes and impacts neuronal survival. J Neurosci 2010, 30:6838-6851.

20. Simons M, Raposo G: Exosomes-vesicular carriers for intercellular communication. Curr Opin Cell Biol 2009, 21:575-581.

21. Cajanek L, Adlerz L, Bryja V, Arenas E: WNT unrelated activities in commercially available preparations of recombinant WNT3a. J Cell Biochem 2010, 111:1077-1079.

22. Zhang W, Wang T, Pei Z, Miller DS, Wu X, Block ML, Wilson B, Zhang W, Zhou Y, Hong JS, Zhang J: Aggregated alpha-synuclein activates microglia: a process leading to disease progression in Parkinson's disease. FASEB J 2005, 19:533-542.
23. Davenport CM, Sevastou IG, Hooper C, Pocock JM: Inhibiting p53 pathways in microglia attenuates microglial-evoked neurotoxicity following exposure to Alzheimer peptides. J Neurochem 2010, 112:552-563.

24. Takada R, Satomi Y, Kurata T, Ueno N, Norioka S, Kondoh H, Takao T, Takada S: Mononsaturated fatty acid modification of Wnt protein: its role in Wnt secretion. Dev Cell 2006, 11:791-801.

25. Willert K, Brown JD, Danenberg E, Duncan AW, Weissman IL, Reya T, Yates JR 3rd, Nusse R: Wnt proteins are lipid-modified and can act as stem cell growth factors. Nature 2003, 423:448-452.

26. Guescini M, Genedani S, Stocchi V, Agnati LF: Astrocytes and glioblastoma cells release exosomes carrying mtDNA. J Neural Transm 2010, 117:1-4.

27. Potolicchio I, Carven GJ, Xu X, Stipp C, Riese RJ, Stern LJ, Santambrogio L: Proteomic analysis of microglia-derived exosomes: metabolic role of the aminopeptidase CD13 in neuropeptide catabolism. J Immunol 2005, 175:2237-2243.

28. Tamboli IY, Barth E, Christian L, Siepmann M, Kumar S, Singh S, Tolksdorf K, Heneka MT, Lutjohann D, Wunderlich P, Walter J: Statins promote the degradation of extracellular amyloid $\beta$-peptide by micoglia via stimulation of exosomes-associated insulin degrading enzyme (IDE) secretion. J Biol Chem 2010, 285:37405-37414.

29. Bianco F, Perrotta C, Novellino L, Francolini M, Riganti L, Menna E, Saglietti L, Schuchman EH, Furlan R, Clementi E, Matteoli M, Verderio C: Acid sphingomyelinase activity triggers microparticle release from glial cells. EMBO J 2009, 28:1043-1054.

30. Blitzer JT, Nusse R: A critical role for endocytosis in Wnt signaling. BMC Cell Biol 2006, 7:28.

31. Savina A, Fader CM, Damiani MT, Colombo Ml: Rab11 promotes docking and fusion of multivesicular bodies in a calcium-dependent manner. Traffic 2005, 6:131-143.

32. Loomis RJ, Holmes DA, Elms A, Solski PA, Der CJ, Su L: Citron kinase, a RhoA effector, enhances HIV-1 virion production by modulating exocytosis. Traffic 2006, 7:1643-1653.

33. Hooper C, Taylor DL, Pocock JM: Pure albumin is a potent trigger of calcium signalling and proliferation in microglia but not macrophages or astrocytes. J Neurochem 2005, 92:1363-1376.

34. Hooper C, Pinteaux-Jones F, Fry VAH, Sevastou IG, Baker D, Heales SJ, Pocock JM: Differential effects of albumin on microglia and macrophages; implications for neurodegeneration following blood-brain barrier damage. J Neurochem 2009, 109:694-705.

35. Zhou T, Hu Y, Chen Y, Zhou KK, Zhang B, Gao G, Ma JX: The pathogenic role of the canonical Wnt pathway in age-related macular degeneration. Invest Ophthalmol Vis Sci 2010, 51:4371-4379.

36. Faure J, Lachenal G, Court M, Hirrlinger J, Chatellard-Causse C, Blot B, Grange J, Schoehn G, Goldberg Y, Boyer V, Kirchhoff F, Raposo G, Garin J, Sadoul R: Exosomes are released by cultured cortical neurones. Mol Cell Neurosci 2006, 31:642-648.

37. Mathivanan S, Ji H, Simpson RJ: Exosomes: extracellular organelles important in intercellular communication. J Proteomics 2010, 73:1907-1920.

38. Chavez-Munoz C, Kilani RT, Ghahary A: Profile of exosomes related proteins released by differentiated and undifferentiated human keratinocytes. J Cell Physiol 2009, 221:221-231.

39. Simpson RJ, Jensen SS, Lim JW: Proteomic profiling of exosomes: current perspectives. Proteomics 2008, 8:4083-4099.

40. Qazi KR, Gehrmann U, Domange JE, Karlsson MC, Gabrielsson S: Antigen loaded exosomes alone induce $\mathrm{TH}-1$ type memory through a B cell dependent mechanism. Blood 2009, 113:2673-2683.

41. Pfeiffer S, Vincent JP: Signalling at a distance: transport of wingless in the embryonic epidermis of drosophila. Semin Cell Dev Biol 1999, 10:303-309.

42. Greco V, Hannus M, Eaton S: Argosomes: a potential vehicle for the spread of morphogens through epithelia. Cell 2001, 106:633-645.

43. Chairoungdua A, Smith DL, Pochard P, Hull M, Caplan MJ: Exosome release of +1-catenin: a novel mechanism that antagonizes Wnt signaling. I Cell Biol 2010, 190:1079-1091.

44. Soleti R, Martinez MC: Microparticles harbouring sonic hedgehog: role in angiogenesis regulation. Cell Adh Migr 2009, 3:293-295.

45. Tizon B, Ribe EM, Mi W, Troy CM, Levy E: Cystatin C protects neuronal cells from amyloid $\beta$-induced toxicity. J Alz Dis 2010, 19:885-894 
46. Theuns J, Remacle J, Killick R, Corsmit E, Vennekens K, Huylebroeck D, Cruts $\mathrm{M}$, Broeckhoven CV: Alzheimer-associated C allele of the promoter polymorphism $-22 \mathrm{C}>\mathrm{T}$ causes a critical neuron-specific decrease of presenilin 1 expression. Hum Mol Genet 2003, 12:869-877.

47. Kingham PJ, Cuzner ML, Pocock JM: Apoptotic pathways mobilized in microglia and neurones as a consequence of chromogranin A-induced microglial activation. J Neurochem 1999, 73:538-547.

doi:10.1186/1471-2202-13-144

Cite this article as: Hooper et al:: Wnt3a induces exosome secretion

from primary cultured rat microglia. BMC Neuroscience 2012 13:144.

\section{Submit your next manuscript to BioMed Central and take full advantage of:}

- Convenient online submission

- Thorough peer review

- No space constraints or color figure charges

- Immediate publication on acceptance

- Inclusion in PubMed, CAS, Scopus and Google Scholar

- Research which is freely available for redistribution 